Int. J. Electrochem. Sci., 12 (2017) $4664-4676$

\title{
Corrosion Inhibition of Copper by Capparis spinosa L. Extract in Strong Acidic Medium: Experimental and Density Functional Theory
}

\author{
Fadel Wedian ${ }^{1, *}$, Mahmoud A. Al-Qudah ${ }^{1}$ and Ghassab M. Al-Mazaideh ${ }^{2}$ \\ ${ }^{1}$ Department of Chemistry, Faculty of Science, Yarmouk University, P.O. Box 560, Irbid, 22163- \\ Jordan \\ ${ }^{2}$ Department of Chemistry, Faculty of Science, Tafila Technical University, P.O. Box 179, Tafila, \\ 66110-Jordan \\ *E-mail: alwedian@yu.edu.jo
}

doi: $10.20964 / 2017.06 .47$

Received: 11 February 2017 / Accepted: 29 March 2017 / Published: 12 May 2017

\begin{abstract}
Inhibition efficiency of Capparis spinosa (CS) extract on the corrosion of copper metal in $1.0 \mathrm{M}$ nitric acid solution was studied by weight-loss and potentiodynamic measurements. The inhibition efficiency that increases with the rise of the concentrations of CS extract but decreases with the rise of temperature. A maximum inhibition efficiency of $82.7 \%$ was achieved by using $440 \mathrm{ppm}$ of inhibitor. The thermodynamic parameters showed that the adsorption of CS extract on copper is physical, spontaneous, and favored at low temperatures. The adsorption of CS extract on the surface of copper obeyed the Langmuir adsorption isotherm at 25,35 as well as at $45^{\circ} \mathrm{C}$. The weight loss, potentiodynamic, and quantum chemical calculations are in a good agreement and reveal that the CS extract is a good inhibitor of copper in acidic solution.
\end{abstract}

Keywords: Capparis spinosa; copper; corrosion inhibitor; acidic inhibition; DFT.

\section{$\underline{\text { FULL TEXT }}$}

(C) 2017 The Authors. Published by ESG (www.electrochemsci.org). This article is an open access article distributed under the terms and conditions of the Creative Commons Attribution license (http://creativecommons.org/licenses/by/4.0/). 